\title{
The Disgust that Fascinates: Sibling Incest as a Bad Romance
}

\author{
Lydia Kokkola $^{1}$ (D) Elina Valovirta ${ }^{2}$
}

Published online: 21 October 2016

(C) The Author(s) 2016. This article is published with open access at Springerlink.com

\begin{abstract}
This article compares the discourse of sibling incest evident in a corpus of fiction with the discourse found in clinical, sociological and criminal literature. Whereas the former primarily regards the coupling as a bad romance, the latter presents the idea that it is unequivocally harmful. This discrepancy between the two discourses surrounding sexual relationships between brothers and sisters speaks to literary fiction's need for thwarted romances for the purposes of the literary market. A more detailed look into three novels from the corpus, Tabitha Suzuma's Forbidden (2010), Donna Tartt's The Secret History (1992) and Pauline Melville's The Ventriloquist's Tale (1997) shows how this logic of sibling incest as a bad romance works in practice.
\end{abstract}

Keywords Sibling incest · Twincest $\cdot$ Romance $\cdot$ Affect $\cdot$ Fiction $\cdot$ Shame

There are many countries_-including Belgium, Portugal, Russia, Turkey, Japan, South Korea, Ivory Coast, Brazil and Argentina-where sexual relations between adult siblings are not criminalized, although marriage is not permitted. On one hand, what could be more ordinary than sibling relationships and love between siblings in the family? (Flannery 2007). On the other hand, in the English speaking world, sibling love in the form of incest is treated as a sensational, strange phenomenon, particularly in the tabloid media. To mention just a few examples from the worlds of gossip media and pornography, we have Hugh Hefner's former twin girlfriends,

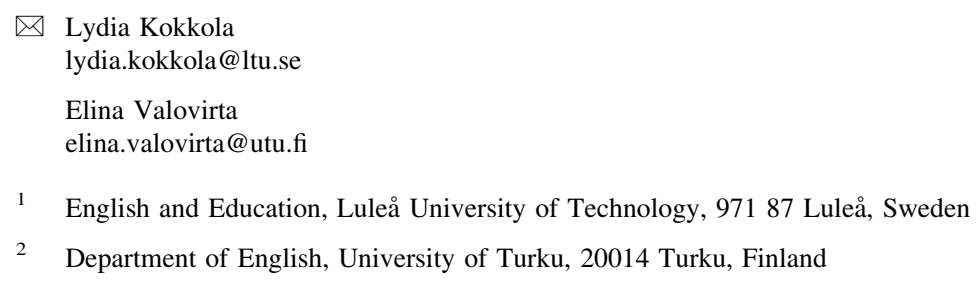


Kristina and Karissa Shannon, the late Whitney Houston's daughter and adopted son who were rumored to marry, and the appearance of the Czech Peters twins in American gay porn. ${ }^{1}$ These examples use the couple's fraternal relation to engender an abject response from the audience. Abjection describes the intertwining of disgust and fascination: the combinatory affect that leads people to stare at car crashes and train wrecks. This paper makes use of a corpus of 29 novels originally written in English depicting sexual desire between siblings, several of whom are twins. Our goal is to examine how this fiction encourages abject responses from readers, even as it presents the relationship as a loving romance. In the fiction, readers are encouraged to align themselves with characters and oppose societal disapproval. We contrast the narrative trajectory that dominates the fiction with empirical research within the domains of psychology, sociology and criminal law to suggest that the fiction presents a singularly limited stance that differs markedly on reports on real life accounts.

Ernestine Schlant describes "literature as the seismograph of a people's moral positions... It reveals even where it is silent; its blindspots and absences speak a language that is stripped of conscious agendas" (1999, p. 2-3). In short, we read the corpus of literature as a cultural expression of collective values. The dominant narrative that emerges from fiction is not of abuse, victimhood and psychological damage, but rather that of thwarted, 'bad' romance. Moreover, the frequency with which this trope appears indicates that sibling incest is what Sara Ahmed would term 'sticky': something which incites a heightened intensity of affect when coming into contact with others (Ahmed, 2004, p. 90). In its stickiness, sibling incest fascinates even as it disgusts. We read this imposition of the familiar (the family, the romance plot) on the acts that are normally secretive (sex and romance between siblings) as a means by which to explore the formation of taboo. Our goal is to defamiliarize the norm of the thwarted romance by pointing to a consistent disjunction between studies of the impact sibling incest has on empirical individuals and its literary portrayal. Our point is not that a handful of authors have chosen to depict sibling incest as a romantic problem, but rather to draw attention to how the 'ordinariness' of romance interacts with the 'strangeness' of incest. In doing so, we hope to critique the generic way in which the 'familiar' is stereotyped as defining the limit of otherness, and so find new ways to access the process of othering. Siblings in love, these novels suggest, are the new normal.

Although corpus approaches have rarely been used in the study of mainstream literatures, they are more common within studies of youth literature when the goal is to be able to form generalizations about a particular phenomenon or to identify underlying patterns and tendencies. The disadvantage that each discussion of a novel must be brief is off-set by the possibility to observe the phenomenon more closely. For instance, noting that one novel presents adoption as a positive outcome for the adopted child is of little relevance, but noting that this is the narrative trajectory in all but one novel in a large corpus of fiction for teens, as Lydia Kokkola

\footnotetext{
${ }^{1}$ See, for example: http://www.salon.com/2010/05/21/twincest/, http://www.dailymail.co.uk/tvshowbiz/ article-2551623/One-month-married-Whitney-Houstons-daughter-Bobbi-Kristina-new-husband-NickGordon-kiss-cuddle-Georgia.html and http://en.wikipedia.org/wiki/Kristina_and_Karissa_Shannon.
} 
does (2013, p. 67-72), exposes a singularly limited pedagogic intent to influence the mind-set of young readers. While we do not claim there is a shared, conscious intent by the authors of the books in the corpus to influence readers to adopt a certain mind-set towards sibling incest, we do suggest that the uniformity with which they portray sibling incest reveals a social discourse.

Our use of the term 'discourse' draws on the work of Michel Foucault. Before Foucault, the term belonged exclusively to linguistics to refer to connected units of language. Foucault drew attention to how the production of knowledge through language contributes to the formation and maintenance of power. As he explains,

in any society there are manifold relations of power which permeate, characterise and constitute the social body, and these relations of power cannot themselves be established, consolidated nor implemented without the production, accumulation, circulation and functioning of a discourse. There can be no possible exercise of power without a certain economy of discourses of truth which operates through and on the basis of this association (Foucault 1980, p. 93). A Foucauldian approach allows us to uncover the exercise of power within discussions of sibling incest. Vikki Bell (1993), arguing from a feminist perspective, also draws heavily on Foucault's notion of discourse to observe that incest is invariably posited as a three-fold problem in the British legislative context: one of health, harm, and family (1998, p. 147). Consensual incest, in turn, is very much absent from her discussion (Bell 1993, p. 155). As we contrast the discourse of consensual incest found in the fiction with the discourses of abuse and harm found in academic studies, we endeavor to uncover the contradictory values held simultaneously.

Our focus on material written in English does not allow us to draw universal conclusions, and indeed the material may well be reflecting a prudery that is, at best, WEIRD (Western, Educated, Industrialized, Rich and Democratic), and may even be specifically Anglo-Saxon. The term 'WEIRD' was introduced in Behavioral and Brain Sciences by Henrich, Heine and Norenzayan, who noted how the claims about human psychology and behavior were almost exclusively based on samples drawn from WEIRD populations, and challenged the idea that these samples were truly representative of the human species. Henrich, Heine and Norenzayan even went so far as to suggest that "members of WEIRD societies, including young children, are among the least representative populations one could find for generalizing about humans" (2010, p. 61). Respondents to their claims, including those published in the same issue as the original claim, do not universally agree with the claim that WEIRD societies are the least representative. For our study, since we are concerned with the role of language in the formation of discourses of power, universality is of less interest than the contrasts evident within one and the same socio-linguistic environment. To illustrate our argument, we begin with a brief overview of the corpus of novels on sibling incest. Thereafter, we examine three novels in more detail-Forbidden Love (2010) by Tabitha Suzuma, The Secret History (1992) by Donna Tartt and The Ventriloquist's Tale (1997) by Pauline Melville-to show in detail how novels that seem very different present a decidedly uniform image of sibling incest as a bad romance, even if their functions within the narrative vary. 
Throughout the discussion, references to studies of lived experiences-drawn from the populations described in the novels-are used to demonstrate that the fiction is not endeavoring to reflect lived reality, but rather exploiting readers' simultaneous disgust and fascination.

\section{The Invisibility of 'Real' People: Fiction and Faction}

At the risk of stating the obvious, fiction should never be expected to tell us the truth about human lives. Nevertheless, from Aristotle to Martha Nussbaum (2010) and from Freud to recent investigations using fMRI techniques to examine how readers' brains when they read (Turner 2008), arguments in favor of literature highlight its capacity to enable readers to reflect on their lives. Fiction puts forth political ideas, exposes patterns of power and allows space to reflect on the implications of scientific findings. Many schools of literary analysis are closely aligned with global concerns (post-colonialism, feminism and post-humanism, for instance). When we compare our corpus of fiction with studies of so-called 'real people', we are not suggesting that the fictional characters 'should' be portrayed with the diversity found in empirical studies: authors of novels are under no obligations to reflect reality. In contrast, scientific or clinical studies are indeed expected to reflect reality, and this expectation may blind us to the impossibility of obtaining such data. There is no shortage of research on sibling incest, but most studies focus on cases of abuse. This is hardly surprising since the goal of research is-generally speakingpredicated on the belief that it will contribute to life-quality. As a result, the very varied work conducted on this topic is deliberately skewed to focus what may be a very small minority. ${ }^{2}$

Determining the prevalence of sibling incest among the general population of any given culture is nigh on impossible due to the simple logistics of asking a representative sample of the population to answer such sensitive-and potentially incriminating - questions. An early attempt by David Finklehor examined 796 undergraduate students at six New England universities (1980). Although the size of the sample is impressive, and the convenience of the sampling technique understandable, it can only be generalized to a population of people who have been able to achieve sufficiently well enough to gain entrance to university, and who have the financial means to cover fees and so on. Finkelhor himself points out that the sample is also not representative in terms of race, rural vs city childhoods and the age at which the students began their undergraduate degrees. He found that $15 \%$ of females and $10 \%$ of males reported some form of sexual contact with a sibling which he suggests are "almost certainly underestimates" mainly due to feelings of shame about reporting such activities or because they have forgotten $(1980,174)$. Of the reported cases, $25 \%$ involved force meaning that $75 \%$ were

\footnotetext{
${ }^{2}$ Accordingly, as literary scholars our reading of psychological and medical literature may be skewed, in that we are equipped by training to critically assess the accuracy of literary studies on sibling incest and are more reliant on the trustworthiness of the life sciences' accounts on the topic. We deem this risk one well worth taking, as comparing competing interpretations of sibling incest generates new visions hitherto undetected.
} 
mutually consensual. The questions that probed the nature of these sexual encounters, however, reveal that consensual activities were primarily limited to fondling with just $2 \%$ of all cases involving intercourse or attempted intercourse. The vast majority of incidents took place when the children were 13-15 years of age. The siblings in our literary corpus, by way of contrast, all include full intercourse between willing partners aged 16 or more. This finding was confirmed by Hardy (2001) who reports that $7 \%$ of his respondents had had sexual contact with siblings, of which $80 \%$ were consensual and most were restricted to fondling.

Our corpus is not a random selection either. It was originally formed whilst we were investigating other aspects of sexuality in literature, and we noticed the sibling incest trope appeared with unexpected frequency. Then we began to actively seek out novels originally written in English with this theme. The collection depicts a diverse range of cultures: British (Ian McEwan), Indian (Arundhati Roy), Nigerian (Chimamanda Ngozi Adichie), Australian (Sonya Hartnett), Mexican (Jennifer Clement), American (John Irving) and Guyanese (Pauline Melville). A few of the novels could be classified as fantasy (Burgess' Bloodtide 2001) or magic realist (Melville's The Ventriloquist's Tale 1997), although the majority are written in the realist mode. There is a blend of high-brow, literary works, many of which have a popular appeal: Donna Tartt's The Secret History (1992), for instance, was on the New York Times and Publishers' Weekly best-seller lists for nine and thirteen weeks respectively. Sibling incest is also a major strand within erotica, and we have included some examples of such works in our corpus. Some are intended for adolescent readers (Robert Cormier, Tabitha Suzuma), although most are written for adults. The decision to include novels intended for different age ranges was based on the widely expressed belief that youth literature is a vehicle by which adults communicate with their young and express their hopes for the future (Kokkola 2013; Trites 1998). Although sexual desire is rife in literature for teens, pornographic desires are not marketed for youth. If positive affects are encouraged in adult-adult communication, the underlying motivation may be pornographic, but if the same traits are also found in literature for youth, we must look beyond the purely sexual to consider why this romance script-siblings caught in a bad romance-is so sticky.

Our focus is on fiction produced from the 1970s onwards, omitting classical novels such as Jane Austen's Mansfield Park (1814), Daniel Defoe's Moll Flanders (1722), Henry Fielding's Joseph Andrews (1742), and Frances Burney's Evelina (1778). These novels have already been examined by Adam Kuper (2009), who argues that bourgeois England was established on a foundation of incestuous relationships between the few families of high rank which tended to intermarry. This social practice, he argues, is reflected in 18 and 19th century fiction, and Horner and Zlosnik (2009) observe the particular frequency with which incest trope is deployed in Gothic fiction. Unlike Kuper, however, we do not regard the novels in our corpus as reflecting a lived reality, but rather as using the stickiness of sibling incest to produce abject affects from the reader. Whilst not in any formal sense 'representative', the heterogeneity of these novels is such that we conclude that points of similarity in portrayals of sibling incest are expressive of a larger cultural 
discourse: sibling incest in English-language narrative fiction forms and informs knowledge within society.

In the first of the three novels we discuss further, Forbidden (2010) by British Tabitha Suzuma, the incestuous siblings, Lochan and Maya, function as parents for their three younger siblings. Their father left the family when Lochan was twelve, but the wrath of the novel is poured on their mother who is romantically engaged with a man nine years her junior. The second novel under scrutiny, Tartt's The Secret History, is an American novel written for adults which contains elements of the Gothic novel in its depiction of a small town student who endeavors to educate himself out of financial and cultural poverty by studying classics at a fictional New England University. In the novel, the protagonist Richard's classmates, Charles and Camilla, a pair of fraternal twins, are gradually revealed to be sexually intimate and violently jealous of each other's other relationships. The final text, The Ventriloquist's Tale by Pauline Melville, is set in Guyana. The novel uses an Amerindian myth about sibling incest to uncover tensions between British colonial culture and the indigenous cultures of the savannah. The children are the offspring of a Scottish man who has two Amerindian wives, who are also sisters. Although the brotherDanny-initially tricks his sister (Beatrice) into having sex, the pair form a loving bond during an eclipse of the sun. The child born of their union-Sonny-takes the story into the next generation. Whilst Forbidden alternates between focalizing through the two protagonists in alternate chapters (enabling the reader to recognize their mutual desire before they acknowledge it themselves), The Secret History and The Ventriloquist's Tale-despite their very different focalization patterns and narrative style - both highlight the impact of sibling incest on others around them. We use these three examples to show how the bad romance trope is depicted in this only superficially diverse set of novels, and make references to other works from the corpus in passing to indicate how common each feature we uncover might be considered.

\section{Recreating the Family: Forbidden}

Tabitha Suzuma's British novel, Forbidden (2010), recounts the story of the incestuous sibling pair, Lochan (aged seventeen) and Maya (aged sixteen), who are the children of a dysfunctional mother who leaves her five children to fend for themselves whilst she settles into a new life with her boyfriend who is nine years her junior. In her absence, Lochan and Maya function as parents for their young siblings Willa (aged five), Tiffin (aged eight) and Kit (aged thirteen). Their adult responsibilities, their sense of duty as they take on the daily grind of feeding, dressing and cleaning up after their siblings, as well as sorting out both their own school issues and those of their younger siblings are contrasted with their mother's immaturity and lack of responsibility. Readers are positioned to admire Lochan and Maya for their parenting skills and to condone the romance that blossoms between them. The younger children are aware that Lochan and Maya's relationship is changing, but only Kit understands how. He keeps it a secret to prevent the siblings from being placed in care, but then exposes them in a fit of rage over an unrelated 
school matter. Lochan is arrested and commits suicide in order to ensure that the remaining siblings are not separated. His actions ensure that the officials read Lochan as a perpetrator and Maya as a victim, although the novel consistently rejects this interpretation. The story ends with Maya still acting as mother to the younger two, and Kit remorsefully taking on Lochan's former responsibilities. Their mother's return is not presented as an option, and indeed the elder siblings do seem more caring than her.

The set up closely resembles that of both V. C. Andrews' Flowers in the Attic and Ian McEwan's novel, The Cement Garden, both of which have received lavish critical praise. In all three novels, the older children become parents to the younger children in the absence of their real parents. Lochan and Maya, like Cathy and Christopher in Andrews' novel, are clearly more dedicated to the task than McEwan's Jack and Julie. An important difference between the three novels is that Forbidden has a more complex focalization pattern. Whereas all the events in The Cement Garden are focalized through Jack and Flowers in the Attic through Cathy, the chapters in Forbidden alternate between Lochan's and Maya's perspectives. As a result, the intended young reader is in the privileged position of knowing more than either of the characters; more specifically, readers know that the desire is mutual before the characters do, and this creates a context in which their desires are romanticized. Furthermore, this structure makes empathizing with just one character and/or reading the novel as a perpetrator-victim narrative highly unlikely. The text proffers a 'star-crossed lovers' script.

Recalling that the term 'star-crossed lovers' comes from Romeo and Juliet, Suzuma's inclusion of Shakespeare's play at the beginning of the novel (and Hamlet later in the play when the pair's incestuous desire has been established) presents Lochan and Maya's relationship as a pairing that is wrongly forbidden by society. The existence of obstacles to romance is so established within literary conventions that Denis de Rougement went so far as to claim that the last seven centuries of literary romance have been rewritings of Tristan and Iseult ([1940] 1983; see also Radway 1991 and Pearce 2007 for more recent accounts). Incest is, however, a decidedly different kind of obstacle from a family feud or loyalty to one's king. Produced in a society where same-sex marriages and relationships that cross ethnic and class boundaries are legal but sibling incest is not, Forbidden might simply be seeking a new frontier for generating the well-established, thwarted romance script. The same could be said of most of the novels in the corpus. The endings, like Tristan and Iseult and Romeo and Juliet, differ in terms of how the reader is expected to value the lovers and society. Tristan and Iseult has many different endings, ranging from briar plants growing out of their graves and entwining and Tristan's marriage to a different Iseult in memory of his true love. What these different versions share is that the couple find a way to circumvent social lorewithout changing the society-and their love never dies. The love between Romeo and Juliet does not die either, but the critical difference is that the recognition of their love changes their society as the feuding families are brought together in grief. The novels in the corpus mostly follow the older pattern: society does not change. The ending of Forbidden, with the new constellation in which the remorseful Kit 
must replace Lochan as the father figure to the youngest two siblings, encourages young readers to feel that perhaps society should change.

This formulation of a new nuclear family through sibling incest situates the romance within the family home and as an expression of family dynamics. A review of clinical studies of abusive relations between siblings, summarized by Krienert and Walsh (2011), situates the sexual acts similarly, even though the affects involved are decidedly different. Krienert and Walsh report that the vast majority of incidents (94\%) occurred in the family home, as was the case in the novels, and that sibling incest has been shown the to be more prevalent in families where the parents were physically and/or emotionally absent, engaged in extra-marital affairs, where there was marital strife and/or corporal punishment (see Tidefors et al. 2010, p. 350-351 for a fuller summary). These were all features that were common in the corpus, with a focus on the physical and/or emotional absence of the mother. For instance, A.S. Byatt's Lord and Lady Alabaster in Morpho Eugenia (1992) are emotionally absent and live entirely separate lives; Ian McEwan's parents in The Cement Garden (1978) are both dead; and the mother in Suzuma's Forbidden is divorced but her relationship with a younger man causes her to be absent.

Parental neglect, including the refusal to act when the incest becomes evident, has also been established in the clinical literature as giving rise to siblings seeking to fulfill emotional needs in one another that are not being fulfilled in the parent-child relationship (Haskins 2003; Schwarz et al. 2006; Tidefors et al. 2010). In many of the novels, the union between the siblings arises in response to a crisis between the parents. By forming their bond, the brothers and sisters create what - to at least some of the characters in each novel-appears to be an ideal family unit. The parents are either actually absent or are emotionally incompetent (or a combination of the two). The children then take on the role of "the parental child", as Gloria González-Lopez characterizes incest cases between daughters and fathers, where the mother is absent and 'the conjugal daughter' takes on the role of the mother and wife (González-Lopez 2013, p. 403). The children as parents formation is perhaps most appealing in Forbidden, and this may reflect the young age of intended reader as 'happy endings' and returns to a stable family unit are still the norm in fiction for youth (see also Inglis 1982).

\section{The Secret History: Gothic Frisson}

Sibling incest appears in a broad range of genres, and is a recurring motif in Gothic fiction where it serves to add an element of danger as well as highlighting female sexuality as a site of contestation within the family (Horner and Zlosnik 2009, p. 115). Horner and Zlosnik observe that some writers use Gothic conventions to narrate incest as a way "to possess and control another" (2009, p. 129). Questions of possession, control, and power seem to always follow representations of incest. A close reading of one form of sibling incest, twincest, may reveal us more about the multiple different functions that it can have in a single literary work, and how representations of sibling incest differ from its portrayals in clinical literature. In Donna Tartt's campus crime novel, The Secret History, twincest occurs between the 
orphaned twins, Camilla and Charles. The Secret History's twincest has at least four functions within the narrative. First, like Forbidden it is a failed attempt at repairing a dysfunctional family. Second, it alludes to Greek myths which underlie the plot. Third, the twins' enigmatic relationship heightens suspense, even though the crime has been revealed at the beginning of the novel. The crime is the murder of Bunny, their classmate, who has learned of the accidental killing of a farmer during a recreation of a Greek bacchanalia. Fourth, twincest reflects and constructs the novel's air of decadence and moral decay in a white elite college in New England. The illicit sexual pairing serves to create a divide between and within the elite group of Classics students and the surrounding community. As such, the campus works like a microcosm, as Elaine Showalter (2005, p. 4) has remarked in her study of academic novels from the 1950 s to the present day, and this enclosed microcosm is an ideal setting for twincest. Other gothic novels in the corpus-such as V.C. Andrews' Flowers in the Attic, Ian McEwan's Cement Garden and Helen Dunmore's A Spell of Winter-use isolated houses to create the same effect. In all these novels, the reformulation of a nuclear family and the private space of the family home, is presented as a logical, albeit thwarted solution to a 'broken' family upbringing.

Raised by their grandmother in Virginia, Tartt's Charles and Camilla Macaulay live and study together as freshmen majoring in Greek in Hampden, Vermont. Their sexual relationship is only revealed to the reader once the first-person narrator, Richard Papen, recognizes it. The revelation is subtly foreshadowed as Richard observes them living together. Richard joins the group of five other Classical Greek students slightly later in the autumn term of their freshman year, and so knows little about them or their activities. Richard remains ignorant of the twins' sexual attraction, even though his narration pairs them by mostly referring to them as 'the twins', rather than two different individuals with separate names. Other observations of the twins' behavior may lead the reader to sense their non-filial attachment before Richard overtly acknowledges it. He admits "there was something a tiny bit inexplicable about them, something I was often on the verge of grasping but never quite did" (Tartt 1992, p. 205). More overt hints about Camilla and Charles' relationship occur when Charles enters the twins' shared apartment without knowing that Richard is visiting: "'Milly, my girl,' I heard him call. 'Where are you, honey?"' (Tartt 1992, p. 327). Richard recounts the meeting without further comment, signaling that he is still oblivious to the truth. It is only after Charles is released from jail after a drunk-driving incident, and kisses Camilla passionately upon returning home, that Richard realizes the kiss was "not a brotherly kiss" and feels "astounded" (Tartt 1992, p. 413) by what he is witnessing. After this event, Richard finally asks Francis "Do you think Charles and Camilla ever sleep together?'” (Tartt 1992, p. 413). Shocked at Francis' affirmation, Richard denies ever having thought of such a thing before, even if he has: "I'd attributed this [doubt] to my own mental perversity, some degenerate vagary thought, a projection of my own desire" (Tartt 1992, p. 414). The heavy use of foreshadowing is likely to trigger similar responses from readers, this setting them up to question their own fascination with the elusive pair. 
The twins' symbiotic relationship may also be read as a textual function and allusion to Greek mythology underlining the narrative. In the marriage between Zeus and Hera, brother and sister, Hera's jealousy over Zeus' infidelity generated several arguments between the two, while in the novel, the scenario is reversed as Charles is the jealous one and Camilla has relationships with men other than her brother. The allusions to Greek mythology, including themes of revenge, competition, and pride in the form of hybris, are thus another function that we can see for twincest in the novel: Charles and Camilla are the Zeus and Hera of the mythical story.

A murder mystery at heart, the murder of Bunny is revealed already in the beginning of the narrative, as Richard narrates the story in retrospect. In order to heighten suspense, the narrative needs enigmatic content, and the twins' relationship coupled with Richard's ignorance serves that purpose. The enigmatic nature of the Classics students as separate and privileged from others is created through the secret of the two murders. In addition, the secret of sibling incest serves to connect and divide the group of students, not only to and from each other but also the rest of the world. Their privileged status as students of Greek needs to be maintained, as the group defines itself in opposition to others by their superior knowledge and cult-like following of their professor, Julian Morrow. At the same time, their shared secrets, including knowledge of the twins' sexual relationship, the nights of bacchanalia, and the two murders, are in fact what make them a group.

When Richard begins to uncover these secrets and tells the story in retrospect, knowledge of incest is itself deemed 'sinful' and causes the group to splinter. Lack of knowledge about twincest fuels the story, whereas full disclosure leads to an end, or in fact a dead end. The group of young students proves fragile in the face of secrets and lies, and, eventually, what Showalter (2005, p. 14) refers to as the novel's 'inwardness' turns against itself. At the center of this inwardness, are Charles and Camilla, the incestuous twins, whose relationship along with all other relationships in the novel, fails. In its failure, it also destroys the other on-lookers.

\section{The Ventriloquist's Tale: Relativizing Incest Through Myth}

While Greek mythology as a component of the Gothic campus novel was a part of the twincest theme in Tartt's novel, Guyanese Pauline Melville similarly draws on mythology to construct her magic realist incest story in The Ventriloquist's Tale (1997). The novel features an incestuous pairing of siblings born into a family where the Scottish Alexander McKinnon has married two Amerindian Wapisiana sisters, Zunai and Maba. The local priest, Father Napier, frowns on the bigamous nature of the relationship, but seems relatively comfortable with the fact that the two wives are sisters. The brother-sister romance in the novel between McKinnon and Maba's children, Danny and Beatrice, intertwines with Amerindian mythology, cosmology and the history of colonialism, denoting how the Christian civilizing mission in the early 20th century Guyanan bush instills hitherto unfelt shame and disgust in Danny, which ultimately breaks them up. Danny, in the end, is a violent alcoholic and Beatrice, for her part, having relocated to Canada, externalizes the 
events and only approaches the subject in her dreams. Once again, sibling incest is a bad romance, even if it is used to destabilize and relativize fixed truths within the postmodern narrative.

The unorthodox marriages of Danny and Beatrice's parents invite the idea that incest is a response to familial, which, according to Leonore Davidoff, dominated interpretations of incest in the 20th century (Davidoff 2006, p. 29). In The Ventriloquist's Tale, however, incest fails to be solely explained as "parental failure" (ibid.). Rather, the novel's utilization of the incest theme and myth serve its “counter-discursive strategy" (Thieme 2001, p. 171), which aims to destabilize fixed truths and emphasize the magical element of this seemingly realist text. The novel's treatment of the incest theme "in a comparatively understated" way (Thieme 2001, p. 184) calls into question our ability to fully know and interpret it, destabilizing boundaries between real and imaginary, magical and realist. Beatrice and Danny's relationship as fundamentally untranslatable thus shows how sibling incest tests and challenges our epistemological habits, even to the point of madness: Father Napier, so consumed by his belief in Christian marriage as the only acceptable institution of sexuality, loses his sanity and is ordained to the care of a mental asylum; he becomes institutionalized. Their father's response to the incest is likewise to give up his life in Guyana and return to live in England.

Incest as a problem in the novel arises when the WEIRD characters, McKinnon and Napier, learn about it and respond with disgust and outrage (although McKinnon the Westerner himself has no problem living in a polygamous relationship with two sisters). Finding incest a "mortal sin", Father Napier tracks Beatrice and Danny, and succeeds in inciting disgust and shame in Danny, but not in Beatrice. Danny's disgust as an affect activates the drawing of a boundary line, which distances him from Beatrice, who feels their partnership is "natural" and not in any way wrong (Melville 1997, p. 200).

For the native characters such as Beatrice and Danny's mother, Maba, the incest is understandable in light of the Amerindian Wapisiana myth, where it is associated with the eclipse and also with the tapir, who they claim is too lazy to seek a mate and so mates with those nearest to hand. Pondering on her children's romance, Maba consoles herself by thinking that "An eclipse, too, she remembered, was a brother and sister coming together and eloping" (Melville, 1997, p. 180). Danny and Beatrice's romance is compared to several native mythologies by the unidentified narrator, so that a fixed understanding is impossible. The result is not a rejection of shame as WEIRD; the native narrative voice is not to be trusted as any more authentic or reliable than the story's Westerners (Shemak 2005, p. 355). Instead, several versions of a similar story are aligned. For example, in Wai-Wai mythology Nuni makes love to his sister, after which she smears his face with genipap so that she can identify her lover. When his identity is revealed, Nuni was ashamed and used his bow and arrow to create a ladder to the sky. He became the moon (with dark patches to indicate his shame) and his sister became the evening star. The various versions of the eclipse myth in the novel seem designed to discourage readers from making rash judgments or constructing definite truths about the nature of sibling incest, as during an eclipse, our sensory perception is thwarted. Particularly the deeply erotic love-making scene between Beatrice and Danny 
which, importantly, takes place during an eclipse "draws attention to the limitations of readers' abilities to 'see' the 'whole story'” (Shemak 2005, p. 359). The varying responses to incest in the novel (from disgust, horror and madness to relatively accepting) shows how vantage points differ based on the light in which one sees things and the lines one draws in interpreting them.

A similar mythological component is associated with the voodoo twin spirits, the Marassas, in Edwidge Danticat's Breath, Eyes, Memory (1994), but here the allusion is clearly negative. The mother, Martine, recites the folk tale of the twin lovers to justify her manual testing of her daughter, Sophie's, virginity. The inseparable twins as lovers symbolize Martine's unhealthy view of the mother and daughter as one (see Gerber 2011, p. 188), and as such demonstrate her inability to see testing as an incest-like act of sexual violence. An incest myth here thus serves to symbolizeand perhaps to alert the reader to-the illicit psychic or sexual merging, while in Melville's novel the function of incest is more ambivalent and subject to interpretation by different, competing understandings of morality and civilization.

The Ventriloquist's Tale is one of the few novels to result in the production of a child — a son who remains unnamed (he is simply known as 'Sonny')—which signals the taboo nature of his conception. After Sonny's birth, Danny returns to the village to marry Sylvana, and rejects Beatrice's suggestion that she should become his first wife. Beatrice's response to Danny's rejection mimicks the onset of disgust as her grief turns to fury and she has a vomiting fit. She blames Father Napier for Danny's rejection and tries to kill the priest with poison although he survives. Again incest is downplayed in the narratorial comment, when it is explained that Beatrice has to leave the community, because "Vengeance attacks were more terrifying than incest" (Melville 1997, p. 266). Sonny remains in the care of their sister, Wifreda, when Beatrice emigrates to Canada. He is characterized as "a secret made flesh" (Melville 1997, p. 268) and, like his mother, "all Sonny wanted was concealment, secrecy and silence" (Melville 1997, p. 285). Unnamed and thus unknown, like his parents' relationship, Sonny remains outside the realist discourse but cannot be fully contained by myth, either.

To compare, in Bloodtide, a novel that draws heavily on Viking mythology, the sole aim of the incestuous coupling is to produce a child who can defeat the enemy forces led by the sister's husband. And in the realist novel A Spell of Winter, set in pre-WWI Cornwall, the sister has an abortion so late in the pregnancy that - for a few moments - the baby is able to cry. The cry is silenced-implying the child is murdered-and the body is buried where the sister cannot find it, the brother does not know it exists. All the children borne of the fictional siblings we examine serve the same purpose in the narrative: they are sinful secrets made flesh. The enigmatic Sonny ultimately disappears and takes away remnants of the shame and disgust of incest with him. He is thought to have metamorphosed into a jaguar, thus suggesting that a life born out of the illicit pairing escapes realist meaning-making habits brought on by the Western civilizing mission with its strict disciplinary boundaries be they religious, epistemological or sexual. 


\section{Reflections and Realities: Attitudes Towards Sibling Incest}

In a discussion of 'radial' changes in literature for youth, Kim Reynolds comments on how literature is not merely a reflection of existing attitudes, it also contributes to shaping attitudes (2007, p. 114-115). In this second half of the paper, we contrast the attitudes that the fictional literature promotes with those found in the research literature on real people. A key difference, as already noted, is that happy, consensual relationships between siblings are unlikely to be drawn to the attention of psychologists or law enforcement agencies, and sociologists struggle to find reliable information about such behaviors in the general population. Thus we are comparing two highly skewed forms of information-neither of which are necessarily 'truthful' - that have formed and inform the oppositional discourses of the bad romance in fiction and the abusive behaviors addressed by clinicians and those working within the context of law enforcement.

Although many of the novels are complex in terms of plot, imagery style and so on, they are extremely simplified in terms of both what constitutes a sibling and what constitutes incest. In reports on real life scenarios, determining what constitutes a sibling and what constitutes a sexual act is much more complex. In the fiction, the sibling relationship is never compromised by possible grey areas. All the siblings share at least one biological parent, usually two, and in all but one example-Jennifer Clement's The Poison that Fascinates (Clement 2008)-the siblings have also been raised together. It is probably not a coincidence that Clement's novel is also one of the few novels in which one of the siblings is unaware that the other is a sibling (they are cousins on their father's side, but they share the same mother). The sister certainly feels that she has been victimized when she discovers that her brother knew that they were siblings when he began their relationship. Trickery is evident in Melville's The Ventriloquist's Tale and in Burgess's YA novel, Bloodtide, where the brother is tricked by his twin sister whilst she is in a state of metamorphosis, but in these cases the sibling relationship continues even after the initial trickery has been revealed. With these exceptions, the rest of the novels in the corpus depict siblings who are both biologically related through at least one parent and who have grown up together and yet choose to be sexually intimate.

In real life, being raised together does seem to be a major factor in suppressing sexual desire. The first major study of this topic was conducted in 1891 by the Finnish anthropologist, Edward Westermarck, who gave his name to the hypothesis that humans develop a sexual aversion to those with whom they have lived with during childhood. The Westermarck effect is supported by field studies and questionnaire based studies. Recent studies summarized by De Smet et al. (2014) indicate that witnessing their mother nursing and caring for a sibling is a key component in generating the disgust reflex, all of which suggests that co-habitation may be more critical than biology in determining the likelihood of sexual aversion. Those who are related through their parents' union and who have grown up together but who are not biologically related are not consistently treated in the clinical or legal literature as full siblings. Adoptive siblings who have not grown up together 
tend not to be treated as siblings, but there seems little agreement on whether children who are raised together-for instances in Kibbutzes-should be counted as social siblings or not. We have not yet found a work of fiction which invoked the trope of incest in relation to social siblings (although romances amongst teens raised in care are common in both real life and fiction). Perlmutter et al. (1982) attempted to resolve this lack of clarity by introducing the term psychological incest to indicate that the victim experienced the sexual relationship as a violation of the incest taboo. This definition empowers the victim, but also insists on victimhood as part of the definition of incest; sexual relations borne of mutual desire fall outside this definition. The clarity of sibling relationships in the literary novel thus stands in stark contrast even with the definition of sibling incest in clinical research.

Determining what constitutes a 'sexual relationship' is similarly simplified. As already noted, Finkelhor's survey revealed that fondling was by far the most common activity and that full coitus was rare. In the corpus, all but one novel contained full, consensual coitus. The exception-Half of a Yellow Sun (2006) by Chimamanda Ngozi Adichie - is also an exception in that the brother, Ugwu, "had never been sure exactly how he and Nnesinachi [whom he refers to as his sister] were related" (Adichie 2006, p. 8). They are "from the same umunna" (ancestral lineage) and thus cannot marry, but this does not stop Ugwu from desiring her. With this exception - and it may be that the two factors are related-the siblings in the rest of the corpus all engage in full, consensual coitus. Moreover, all the relationships are heterosexual, ${ }^{3}$ whereas a recent, anonymous, on-line survey of 1178 men and 1521 women found that approximately one-third of incestuous relationships between siblings involved same-sex couplings (of which there were almost twice as many instances of sex between brothers as there were between sisters) (Beard et al. 2013; Stroebel et al., 2013).

Unlike the early data from Finkelhor, the recent survey data from the on-line study defines all sexual relationships between family members in terms of abuse. It is published in six reports which identify different constellations of perpetratorvictim pairings, that is, the possibility of mutual desire is ruled out in the very definition. Moreover, the question of volition and the ages of the participants are tightly knitted. Janet DiGiorgio-Miller (1998) uncovered a consistent pattern in the clinical literature for sibling incest to take place between an older aggressor and a younger victim. This pattern was confirmed by Tidefors et al. (2010) who present a comprehensive literature review of sibling incest, with a particular focus on relationships between adolescents as well as Krienert and Walsh (2011) who drew on eight years of reports filed with the U.S. police to define the characteristics of victims, offenders and event characteristics. Indeed, for some researchers, the age gap between siblings is critical. Carter and Dalen, for instance, suggest that sibling incest only occurs "when the older sibling is 5 or more years senior to the younger sibling or when force is used no matter what the age difference" (1998, p. 45). All other cases, Carter and Dalen dismiss as 'playing doctors', and should be deemed an age-appropriate, harmless part of childhood sexual development (see Krienert and

\footnotetext{
${ }_{3}^{3}$ In Ursula le Guin's Left Hand of Darkness, Estraven and his Kemmer are referred to as brothers but at the point when they engaged in coitus, the brother was female.
} 
Walsh 2011; Caffaro and Conn-Caffaro 1998, 2005 for discussions). What these reports share is an assumption that sexual relationships are either abusive or do not exist (it is dismissed as 'playing doctors'). Both DiGiorgio-Miller (1998) and the team led by Inger Tidefors (2010) observe the belief that sibling incest may be beneficial, pleasurable and non-harmful exists, but then argue that their evidence does not support this claim. They, like the team led by O'Keefe and, indeed, the early study by Finkelhor, found strong correlations between sexual relations between siblings and hyper-sexuality in adulthood.

It is worth noting that Caffaro and Conn-Caffaro $(1998,2005)$ observe that sibling incest is even less likely than parent-child incest to be reported to official bodies such as medical practitioners or the police. The possibility that mutual desire is not reported because it is not experienced as problematic is likely. It is also plausible that the fiction is accurate. Anecdotal evidence, such as Season One of the BBC's Call the Midwife, based on the real life experiences of Jennifer Worth, a midwife in 1950s London could be considered evidence of a sort. There is an episode in which the loving, sexual relationship between an elderly pair of siblings is condoned by the nuns although not initially the midwives. The latter change their minds when Sister Evangelina explains that they were separated as children in a workhouse and that the roughness of workhouse life destroyed all sense of family, and treats the pair's capacity to love at all as a miracle. The sister's suicide following the natural death of her brother preserves the romance in perpetuity and the impact it has on the midwives suggests a desire to change society following the Romeo and Juliet script. The extent to which the story based on Worth's memoirs is 'truthful' is impossible to gauge. What we do see, however, is that the discourse that dominates research literature negates the possibility of mutual desire-all sibling couplings are deemed abusive-whereas novels and film adaptations revel in the presentation of loving, albeit thwarted, romances between heterosexual siblings.

A further feature of the fiction that encourages readers to read the plot as a romance is that the sister is typically more powerful than the brother. Since males are generally perceived as the aggressors (to the extent that female aggression can be dismissed see O'Keefe et al. 2014), this configuration allows readers to override their expectations that relationships between siblings are abusive (promoted by the professional discourse). The simplest way to empower the sister in a work of fiction, is to make her the older of the two but in cases such as Forbidden, where Maya is younger than Lochan, her youth is off-set by the fact that Lochan has a social disability and finds it difficult to speak to anyone outside his family. Moreover, in all the fiction, the sexual relationships begin when both siblings are post-pubertal, if ages are mentioned, they are both fifteen or above. We regard this as a trope which is designed to encourage the reader to withhold judgment and consider the possibility of the relationship as mutually consensual and non-coercive. If the empowerment of the sister over the brother appeared in just one book, one could dismiss it as an individual choice, but when the pattern is repeated across the corpus, a broader underlying strategy can be detected. The novels downplay the possibility of abuse and consistently attempt to generate positive affect towards the couple. 


\section{Shame, Stigma and the Abject: The Stickiness of Sibling Incest}

As the above discussion has demonstrated, despite the novels' seeming diversity, the sibling incest trope is used to generate a romance that is thwarted by social expectations. All the relationships end badly, death and/or madness being the two most common outcomes, although it is not always the siblings themselves who suffer these consequences. In The Secret History and The Ventriloquist's Tale, it is the on-lookers who suffer most, whereas in Forbidden Lochan's suicide and false confession protects his younger siblings. Whilst we could read these outcomes as punishments for unacceptable behavior, to do so would be to ignore the way in which the novels promote positive affects even when the relationships are decidedly unromantic. The twins in The Secret History are the least positive pairing in the entire corpus, but because the novel is narrated by Richard (who is infatuated by Camilla), the pair are still primarily shown in a positive light. In each novel, sibling incest is sticky: it invites and encourages readers to be fascinated. This ability to promote positive affects towards siblings in lust is noteworthy because it runs counter to the findings in real world settings.

Research by (Royzman et al. 2008) demonstrates that physiological responses to images of sibling incest reveal such an intense disgust that it triggers the nausea reflex. This study, conducted on a convenience sample of American undergraduates, concluded that there was evidence of a "direct link between a particular type of negative moral assessment and a reaction of gustatory discomfort" (107). In short, the kind of person who is likely to read most of the literature in the corpus, literally feels sick when viewing images of siblings engaging in sexual acts. That these novels can override this response and promote the positive affects associated with a romance plot is a remarkable exemplar of how the abject functions.

Although the term 'abject' originates from psychology, it is frequently used to describe the appeal of thrillers and other forms of sensational literature. When something is abject, disgust is tightly coupled with fascination. Fascination is an acute expression of interest, and so too is disgust's close relative, shame; it is activated by unwanted attention from others and felt as an exposure (Ahmed 2004, p. 103). Shame is then a dynamic affect that produces effects in individuals, like turning away or covering our faces with hands. In addition, shame is contagious (Sedgwick 2003, p. 36) as evidenced, for example, by Danny in Ventriloquist's Tale, who contracts shame and disgust from outside. Shame-and its associated affects of disgust and guilt (shame with a known perpetrator)—has 'stuck' hard with sexuality since the Enlightenment (Davidoff 2006, p. 27). This historically 'sticky' (Ahmed 2004, p. 90) nature of shame and its related affects in connection with sexuality means they have become ordinary and familiar-in a word, normal. If siblings having sex is the new normal, as we claimed in the beginning of this article, so, too, are shame and its sisters.

For instance, in Sonya Hartnett's Sleeping Dogs, set in the Australian outback, Michelle and her younger brother, Jordan, feel guilty about their relationship, even as they feel compelled to continue it. Their solution is to accept their father's 
frequent physical attacks as a punishment which gives them the 'right' to continue their relationship.

They knew what they did wasn't right... If Griffin hit Jordan, wasn't that a sort of punishment for them? And if they were being punished, didn't that give them the freedom to go on doing what they did? 'Do you see what I mean, Jordan?' [Michelle] asked. 'Sometimes, two wrongs can make a right. Can give you a right' (Hartnett 1995, p. 18; italics original). Sleeping Dogs is unusually clear in its dismissal of guilt by accepting punishment, but guilt itself is present for at least one sibling (more typically both) in all the novels, even those with mythological underpinnings.

The existence of series within erotica devoted to these desires suggests that disgust is profoundly attached to fascination, and this odd balance is profoundly engaging. For example, Susanna Paasonen (2011, p. 108) remarks that incest stories are among the most popular on Literotica, an amateur erotic story website. ${ }^{4}$ Like the erotica Paasonen examines, these tales of sibling incest are marketable commodities which portray sibling incest as deeply romantic.

The taboo of incest is turned into a bad romance in its multiple senses: they do not end well, and are despite their romantic nature the results are harmful, ill, or faulty. They are, to use Pearce's term, 'anti-romances' (2007, p. 182); romances which are destined to fail. In the bad romance of sibling incest, taboo is the preoccupation, not the happy end. While disgust draws a boundary line in the face of that which is intuitively experienced as wrong, that seam or a contact zone (see Ahmed 2004, p. 85), it is conspicuously absent in the act and experience of sibling incest in the novels we have discussed. When it arises, like in The Ventriloquist's Tale, it only arises retrospectively as a consequence of internalized judgment from outside. As a contact zone, disgust draws an affective-moral boundary, without which there is no taboo. Disgust is thus crucial to power relations (Ahmed 2004, p. 88), and lies at the heart of taboo. Sibling incest as a romance fulfills its purpose as a taboo which is disgusting, fascinating, and romantic all at the same time.

\section{The Circle of Shame}

Shame is a culturally specific affect, and in this paper we have only considered literature written in English and research studies conducted in Anglophone countries. The legacy of Anglo-Saxon prudery may well mean that similar results would not be found in other contexts. The Wapisiana myth that enables the mother to come to terms with her children's relationship in The Ventriloquist's Tale is just one instance within the corpus where another culture is shown to generate different affects. (In this novel, the Europeans are unable to cope, and are driven mad by their knowledge. The indigenous population are only mildly flustered.) The culturally

\footnotetext{
${ }^{4}$ Since Paasonen's survey of erotic story categories on www.literotica.com, the number of stories in the category Incest/Taboo ('Keeping it in the family') has risen to 33,151 (in May 2015). The stories are further categorized into tags such as 'brother sister incest', 'brother sister sex', 'sister', 'brother', 'siblings' and 'sibling incest'.
} 
specific nature of shaming is self-perpetuating. In the context of sibling incest it generates a circular argument. Sexual relations between siblings, in both the real life studies (Carlson et al. 2006; Krienert and Walsh 2011) and in our collection of fiction, result in feelings of confusion and shame.

The presence of shame could suggest that the behavior is inherently wrong. However, because shame is a cultural phenomenon, the argument becomes circular: sibling desire incites shame because it is wrong, and it is wrong because it incites shame. If we step outside this circle, as comparing clinical and literary representations of the same phenomena allows us to do, we see two opposing discourses. The clinical literature defines incest in terms of abuse, and even the sociological data that has the potential to capture the presence of loving relationships is interpreted within a discourse of negative outcomes and violent behaviours. The fiction toys with the tension between desire and guilt as it invites readers' to empathise with the characters' desires, encouraging them to condone behaviors the work on the disgust reflex suggest they would normally oppose. By using a corpus approach, we have shown that this is not limited to erotica or just a few books, and our more detailed readings of the three novels show how this engineering of positive affects works in practice.

The telling of these sibling incest stories within the commercial context of fiction plays into contemporary discourses of abjection and taboo. The taboo nature of sibling incest makes it perpetually 'strange', even if it is made 'ordinary' within the romance framework. Clinical literature discussing the impact of sibling incest, on the other hand, proves under our scrutiny to deem consensual sibling incest unequivocally harmful for those engaged in it, thus making the 'ordinary'- the family, home, and sibling relations-'strange' in contributing to the taboo of such sexual transgressions. Consensual sibling incest as viewed in clinical literature and portrayed by fiction, and as argued in this article, is a bad romance whose impact and consequences are harmful for the individuals engaged in it. These bleak vistas for incestuous siblings' romance are portrayed in different tones: while clinical research condemns it, fiction is more flexible in allowing bad romance to drive the plot and titillate readers. Trapped between these competing, incompatible discourses, 'truth' and 'reality' are silenced.

Acknowledgments Elina Valovirta's funding from the Academy of Finland.

Open Access This article is distributed under the terms of the Creative Commons Attribution 4.0 International License (http://creativecommons.org/licenses/by/4.0/), which permits unrestricted use, distribution, and reproduction in any medium, provided you give appropriate credit to the original author(s) and the source, provide a link to the Creative Commons license, and indicate if changes were made. 


\section{Appendix: Corpus of Sibling Incest Novels}

Adichie, C. N. (2006). Half of a yellow sun. London: Harper Perennial.

Albaugh, A. (2015). Forbidden arrangement. Kindle Edition ASIN: B00ZS0GZ74.

Andrews, V. C. (1979). Flowers in the attic. New York: Simon \& Schuster.

Biscotti, N. (2014). Brother knows best. Alpena, MI: Excessica Publishing.

Burgess, M. (2001). Bloodtide. London: Penguin.

Byatt, A. S. (1992). Morpho eugenia (in collection Angels and Insects). London: Chatto \& Windus.

Call the Midwife. BBC. 2012-2015. DVD.

Carter, A. (1974). The executioner's beautiful daughter (in collection Fireworks: Nine Profane Piece). London: Quartet Books.

Clement, J. (2008). The poison that fascinates. Edinburgh: Canongate Books Ltd. Cormier, R. (2004). Fade. Delacorte Books for Young Readers.

Cott, A. (2015). My lovely step brother. Kindle Edition ASIN: B00SDLIDUW.

Danticat, E. (1994). Breath, eyes, memory. London: Abacus.

Dunham, L. (2014). Not that kind of girl. New York: Random House.

Dunmore, H. (2001). A spell of winter. Grove Press.

Eugenides, J. (2002). Middlesex. New York: Farrar, Straus and Giroux.

Hartnett, S. (1995). Sleeping dogs. New York, NY:Viking.

Irving, J. (1981). The hotel New Hampshire. New York: Dutton.

Kitt, S. (2011). In the barn. Alpena, MI: Excessica Publishing.

Le Guin, U. K. (1969). The left hand of darkness. New York: Penguin.

Martin, G. R. R. (1996). A game of thrones. London: Harper Collins.

McEwan, I. (1978). The cement garden. London: Jonathan Cape.

Melville, P. (1997). The ventriloquist's tale. London: Bloomsbury.

Renarde, G. (2013). Adam and Sheree's family business. Alpena, MI: Excessica Publishing.

Roy, A. (1997). The god of small things. New York: Random House.

Selasi, T. (2013). Ghana must go. New York: The Penguin Press.

Suzuma, T. (2010). Forbidden. London: Definitions.

Tartt, D. (1992). The secret history. New York: Alfred A. Knopf.

Tate, N. (2015). Stepbrother, sort of. Kindle Edition ASIN: B00ZSQAMFY.

Vonnegut, K. (1976). Slapstick or lonesome no more. London: Jonathan Cape.

Wesley, M. (1984). The camomile lawn. London: Macmillan.

\section{References}

Ahmed, S. (2004). The cultural politics of emotion. Edinburgh: Edinburgh University Press.

Beard, K. W., O’Keefe, S. L., Swindell, S., Stroebel, S. S., Griffee, K., Young, D. H., et al. (2013). Brother-brother incest: Data from an anonymous computerized survey. Sexual Addiction and Compulsivity, 20(3), 217-253.

Bell, V. (1993). Interrogating incest: Feminism, Foucault, and the law. London and New York: Routledge. 
Caffaro, J. V., \& Conn-Caffaro, A. (1998). Sibling abuse trauma: Assessment and intervention strategies for children, families, and adults. New York: Haworth Press.

Caffaro, J. V., \& Conn-Caffaro, A. (2005). Treating sibling abuse families. Aggression and Violent Behavior, 10(5), 604-623.

Carlson, B., Maciol, K., \& Schneider, J. (2006). Sibling incest: Reports from forty-one survivors. Journal of Child Sexual Abuse, 15(4), 19-34.

Carter, G., \& Van Dalen, A. (1998). Sibling incest: Time limited group as an assessment and treatment planning tool. Journal of Child and Adolescent Group Therapy, 8(2), 45-54.

De Smet, D., Van Speybroeck, L., \& Verplaetse, J. (2014). The Westermarck effect revisited: A psychophysiological study of sibling incest aversion in young female adults. Evolution and Human Behavior, 35(1), 34-42.

DiGiorgio-Miller, J. (1998). Sibling incest: Treatment of the family and the offender. Child Welfare-New York, 77, 335-346.

Foucault, M. (1980). Power/knowledge: Selected interviews and other writings, 1972-1977. Brighton: Harvester Press.

Gerber, N. F. (2011). Binding the narrative thread: Storytelling and mother-daughter relationship in Edwidge Danticat's Breath, Eyes, Memory. Journal of the Association for Research on Mothering, 2(2), 188-199.

González-Lopez, G. (2013). Incest revisited: A Mexican Catholic priest and his daughter. Sexualities, 16(3/4), 401-422.

Hardy, M. S. (2001). Physical aggression and sexual behavior among siblings: A retrospective study. Journal of Family Violence, 16(3), 255-268.

Henrich, J., Heine, S. J., \& Norenzayan, A. (2010). The weirdest people in the world? Behavioral and Brain Sciences, 33(2-3), 61-83.

Horner, A., \& Zlosnik, S. (2009). Keeping it in the family: Incest and the female Gothic plot in du Maurier and Murdoch. In D. Wallace \& A. Smith (Eds.), The female gothic: New directions (pp. 115-132). Palgrave: Macmillan.

Inglis, F. (1982). The promise of happiness: Value and meaning in children's fiction. Cambridge: CUP Archive.

Kokkola, L. (2013). Fictions of adolescent carnality: Sexy sinners and delinquent deviants. Amsterdam and Philadelphia: John Benjamins Publishing Company.

Krienert, J. L., \& Walsh, J. A. (2011). Sibling sexual abuse: An empirical analysis of offender, victim, and event characteristics in National Incident-Based Reporting System (NIBRS) Data, 2000-2007. Journal of Child Sexual Abuse, 20(4), 353-372.

Kuper, A. (2009). Incest and influence: The private life of bourgeois England. Cambridge: Harvard University Press.

Nussbaum, M. C. (2010). Not for profit: Why democracy needs the humanities. Princeton: Princeton University Press.

O'Keefe, S. L., Beard, K. W., Swindell, S., Stroebel, S. S., Griffee, K., \& Young, D. H. (2014). Sisterbrother incest: Data from anonymous computer assisted self interviews. Sexual Addiction and Compulsivity, 21(1), 1-38.

Paasonen, S. (2011). Carnal resonance: Affect and online pornography. Cambridge: MIT Press.

Pearce, L. (2007). Romance writing. Cambridge: Polity Press.

Perlmutter, L. H., Engel, T., \& Sager, C. J. (1982). The incest taboo: Loosened sexual boundaries in remarried families. Journal of Sex and Marital Therapy, 8(2), 83-96.

Royzman, E. B., Leeman, R. F., \& Sabini, J. (2008). "You make me sick": Moral dyspepsia as a reaction to third-party sibling incest. Motivation and Emotion, 32(2), 100-108.

Shemak, A. (2005). Alter/natives: Myth, translation and the native informant in Pauline Melville's The Ventriloquist's Tale. Textual Practice, 19(3), 353-372.

Showalter, E. (2005). The faculty towers: The academic novel and its discontents. Oxford and New York: Oxford University Press.

Stroebel, S. S., O’Keefe, S. L., Griffee, K., Kuo, S. Y., Beard, K. W., \& Kommor, M. J. (2013). Sistersister incest: Data from an anonymous computerized survey. Journal of child sexual abuse, 22(6), $695-719$.

Thieme, J. (2001). Postcolonial con-texts: Writing back to the canon. London and New York: Continuum.

Tidefors, I., Arvidsson, H., Ingevaldson, S., \& Larsson, M. (2010). Sibling incest: A literature review and a clinical study. Journal of Sexual Aggression, 16(3), 347-360. 
Trites, R. S. (1998). Disturbing the universe: Power and repression in adolescent literature. Iowa City: University of Iowa Press.

Turner, A. P. (2008). Incest, inbreeding, and intrafamilial conflict: Analyzing the boundaries of sexual permissiveness in modern North America. Sexuality and Culture, 12, 38-44. 